\title{
THE RELATION OF BIOCHAR TEXTURE TO ITS PHYSICOCHEMICAL AND MORPHOLOGICAL CHARACTERISTICS
}

\author{
Michal KALINA, Šárka SOVOVÁ, Monika TRUDIČOVÁ, Jan HAJZLER, Jiř́i SMILEK, \\ Vojtěch ENEV, Ludmila MRAVCOVÁ
}

Brno University of Technology, Faculty of Chemistry, Brno, Czech Republic, EU, kalina-m@fch.vut.cz

https://doi.org/10.37904/nanocon.2020.3760

\begin{abstract}
Biochar represents ubiquitous material produced by pyrolysis of various organic materials. Mainly the biochar originating from waste organic biomass residues represents highly attractive material with the possible utilization as a soil conditioner in agriculture. For these purposes, the knowledge of biochar chemical composition, its potential stability in soils, the knowledge of the elements and molecules, which can be released from biochar to surroundings and the relation of these properties to the actual texture of used material, seems to be highly important to predict the potential effect on soil and environment. This area represents the topic of present work, where we focused mainly on the effect of biochar texture to internal microstructure obtained by SEM and BET analysis and the content of organic matter. The results have shown, that the more developed internal structure of biochar with the larger specific surface area can be correlated with the higher content of aromatic regions formed by the organic structures with the high contents of the organic carbon. The high content of organic matter and organic carbon is assumed to be beneficial for agricultural application of biochar.
\end{abstract}

Keywords: Biochar, particle size, specific surface area, organic matter

\section{INTRODUCTION}

7.8 billion people are living on our planet right now and this number is constantly increasing. Therefore, more and more food will be necessary for the consumption of humanity. The soil is the most important for agricultural production, but it is already depleted and today's way of cultivating the land does not help it much either. It is not only erosion but also lack of organic matter, aridity and salinity is the problem. One of the possible solutions could be the use of soil conditioners such as lignite, lignohumate, alginate or biochar to improve soil fertility, water retention], enhance plant growth [1,2]. Biochar is a carbon-rich solid product of the thermochemical conversion of biomass under anaerobic conditions (pyrolysis). The attractive chemical properties of biochar are mainly in reducing greenhouse gasses, reducing nutrient $(P, N, M g)$ leaching, enhancing plant growth [3,4]. Physical (e.g. particle size distribution, density, porosity and surface area) and chemical ( $\mathrm{pH}$, electric conductivity, zeta potential, organic carbon and $\mathrm{PAH}$, nutrient content and elemental composition) characteristics of biochar depend on thermochemical (pyrolysis) operating conditions and intrinsic nature of the source biomass [4]. There is a disadvantage in this because biochar is not a standardized product, and its properties are highly variable. In principle, pyrolysis is a process of converting solid biomass into bio-oil, gaseous products, and biochar under oxygen-limited or anoxic environment [5]. Various products serve as a feedstock used for biochar production, ranging from wood-based products (e.g., sawdust, woodchips and wood pellets, tree bark), organic wastes (e.g., manure and sludges,) and plant-based materials (e.g., wheat straw, leaves, husks, seeds and cobs) [6].

Generally, the effect of biochar on soil or plant growth has been widely investigated by many researchers $[4,5,6]$ but only a few studies were focused on biochar characteristics itself. Biochar particle size affects soil 
physico-chemical properties and nutrient contents. The soil treated with biochar of various particle size $(<3,3-$ 6 and $6-9 \mathrm{~mm}$ ) shows generally decrease in the bulk density, increase in porosity, saturation percentage and the soil organic matter in comparison with the soil without biochar treatment. Biochar amendment also showed improvement in the soil mineral N, AB-DTPA (ammonium bicarbonate diethylenetriaminepentaacetic acid, multiextractant) extractable $\mathrm{P}$ and $\mathrm{K}$ over biochar control. In more detail, biochar of the smallest particle size $(<3 \mathrm{~mm})$ shows the maximum improvement of previously mentioned soil properties and to the plant growth parameters (tomato crop) [1]. Alkaline biochar $(\mathrm{pH} 10)$ can be used in acidic soil (e.g. neutralizing the acidity of peat). Different particle fractions of biochar $(<3.3,3.3-6$ and $6-10 \mathrm{~mm})$ were tested for the peat acid neutralizing capacity and the finest fraction has the highest neutralizing power. Although, in comparison with $2.5 \mathrm{~g}$ of calcium carbonate (the most used liming material), it is necessary to use $43 \mathrm{~g}$ of biochar to reach the same liming effect per litre of peat. Nevertheless, biochar shows additional peat-based growing media improvement, such as an increase in air content and higher physical stability during cropping [23]. Biochar nutrient extraction performed by [8] shows that the recovery of $\mathrm{P}, \mathrm{K}$ and $\mathrm{Mg}$ was greater for smaller particle size fractions. Important to note, the size fractions after sieving was much smaller $(0.15-0.60 \mathrm{~mm}, 0.60-1.18$ $\mathrm{mm}, 1.18-4.00 \mathrm{~mm}$ and $>4.00 \mathrm{~mm}$ ) than previously mentioned researches. Here we can see that particle size fractions of the biochar vary with each other significantly. Another study [9] confirmed that particle size fractions of the same biochar have a different amount of total extractable nutrients and $\mathrm{pH}$ level (higher for finer fraction $<1 \mathrm{~mm}$ ). From the other point of view, the quality and quantity of humic substances released from biochar can be affected by grain size as well. Particle size fraction $>1 \mathrm{~mm}$ released humic substances with increasing humification degree, increasing molecular weight and aromaticity. However, there was no effect of $\mathrm{pH}$ on the quantity and quality of humic substances released from biochar. Also, the adsorption energy was the lowest for the finest particles and increased with the size of biochar particles. By contrast, carbon mobility between solid and liquid phases was greatest for the finest fraction $(<1 \mathrm{~mm})$.

Therefore, the experimental part of this work was focused on the description of the relation of the texture of biochar and its the corresponding physicochemical characteristics, morphology and the content of organic matter and organic elements. The provided set of basic characteristics will help to determine the optimal application conditions in agriculture, where we believe could serve biochar as a promising soil supplement.

\section{EXPERIMENTAL}

\subsection{Materials}

The Biochar 1 used in the work was purchased from company Biouhel.cz, s.r.o (Czech Republic). This sample, originating from solid digestate from biogas plants, was produced by pyrolysis at $450{ }^{\circ} \mathrm{C}$ as a sample specifically for the use in agriculture. Biochar 2 and 3 were selected from the declared list the official European producers of biochar having the official EBC certificate (https://www.european-biochar.org/en/home) [10]. The sample of Biochar 2 (Sonnenerde, Austria) originated from crop biomass residues pyrolyzed at $600{ }^{\circ} \mathrm{C}$ using PYREG technology. The source biomass of Biochar 3 (Novocarbo, Germany) was originating from wood chip and softwood residues, which were pyrolyzed at $600{ }^{\circ} \mathrm{C}$ using PYREG technology.

\subsection{Sample pre-treatment and fractionation}

The individual biochar samples were air-dried in the oven at $45^{\circ} \mathrm{C}$ for 48 hours. The pre-treated samples were subsequently fractionated using laboratory sieve shaker (AS-200, Retsch $\mathrm{GmbH}$ ) on the following fractions:

- fraction $A$ - grain size under $0.5 \mathrm{~mm}$

- fraction $B$ - grain size from 0.5 to $2 \mathrm{~mm}$

- $\quad$ fraction $\mathrm{C}$ - grain size from 2 to $4 \mathrm{~mm}$

- fraction $\mathrm{D}$ - grain size above $4 \mathrm{~mm}$ 


\subsection{Scanning electron microscopy}

The visualization of internal structure and porosity was realized using the scanning electron microscopy (SEM) imaging. For purposes of this analysis, small parts of the biochar specimen were selected. These specimens were subsequently gold-coated in a sputtering device and investigated using a scanning electron microscope ZEISS EVO LS 10 in the mode of secondary electrons (SE). The accelerating voltage was set to $5 \mathrm{kV}$.

\subsection{BET analysis}

The specific surface area of individual biochar samples was characterized using a NOVA 2200 analyser (Quantechrome Instruments) by BET (Brunauer-Emmett-Teller) analysis. Before the analysis, the dried sample was weighted directly into the measuring cell. The sample cell was degassed at increased temperature for 12 hours. The measurement was performed using $\mathrm{N}_{2}$ as an absorption gas.

\subsection{Elemental analysis and thermogravimetry}

The elemental composition of studied biochar samples was determined using a CHNS analyser Euro Vector EA 3000. Samples ( 5 mg) were packed in tin capsules and burned in an oven at $980{ }^{\circ} \mathrm{C}$ using pure oxygen as the combustion gas and pure helium as the carrier gas. The content of organic elements $\mathrm{C}, \mathrm{H}, \mathrm{N}, \mathrm{S}$ was calculated by a calibration curve determined using a reference standard sample of sulphanilamide. The percentage of oxygen content was calculated by difference and the values obtained were corrected for ash and moisture content.

Thermogravimetric analysis was performed by TGA Q5000 (TA Instruments) with an airflow of $60 \mathrm{~mL} \cdot \mathrm{min}^{-1}$. Approximately $5 \mathrm{mg}$ of the sample was sealed in an aluminium crucible and was heated from $25^{\circ} \mathrm{C}$ to $700^{\circ} \mathrm{C}$ with a heating rate of $10^{\circ} \mathrm{C} \cdot \mathrm{min}^{-1}$.

\section{RESULTS AND DISCUSSION}

The insights from the published literature are indicating that the properties of biochar are closely linked to the conditions of pyrolysis [5], the origin of the source biomass [4,5] but also by biochar texture $[7,8,9]$. To be able to provide a complex view on the relation of biochar texture to its possible effect on soil, the representative samples of EBC certified biochar for the use in agriculture were selected and studied in present work. The properties of biochar samples discussed in chapter 3.2 were assessed in respect to obtained view into its internal microstructure as was obtained by SEM and BET analysis discussed in chapter 3.1.

\subsection{Characterization of biochar internal microstructure}

The first method used for a visual illustration of the internal structure of studied biochar samples and its relation to the sample texture was SEM imaging (Figure 1). For purposes of this analysis, the samples of original biochar were pre-treated as was described in chapter 2.2 by simple laboratory sieve shaker.

Figure 2 is showing the visual comparison of the same fractions (Fraction C) of Biochar 1 and Biochar 2 present work. The results of SEM imaging are indicating, that both the samples possessing the EBC certification (Biochar 2 and 3 ) have similar internal microstructure with a broad variety of pore distribution indicating their high potential for their possible utilization in agriculture as a soil conditioner enhancing soils properties (mainly its sorption and water holding capacity). On the other hand, the SEM image of Biochar 1 indicates fine internal structure with low content of internal pores or even more solid particle-like structures instead of porous as would be expected for biochar with the possible agricultural application. 

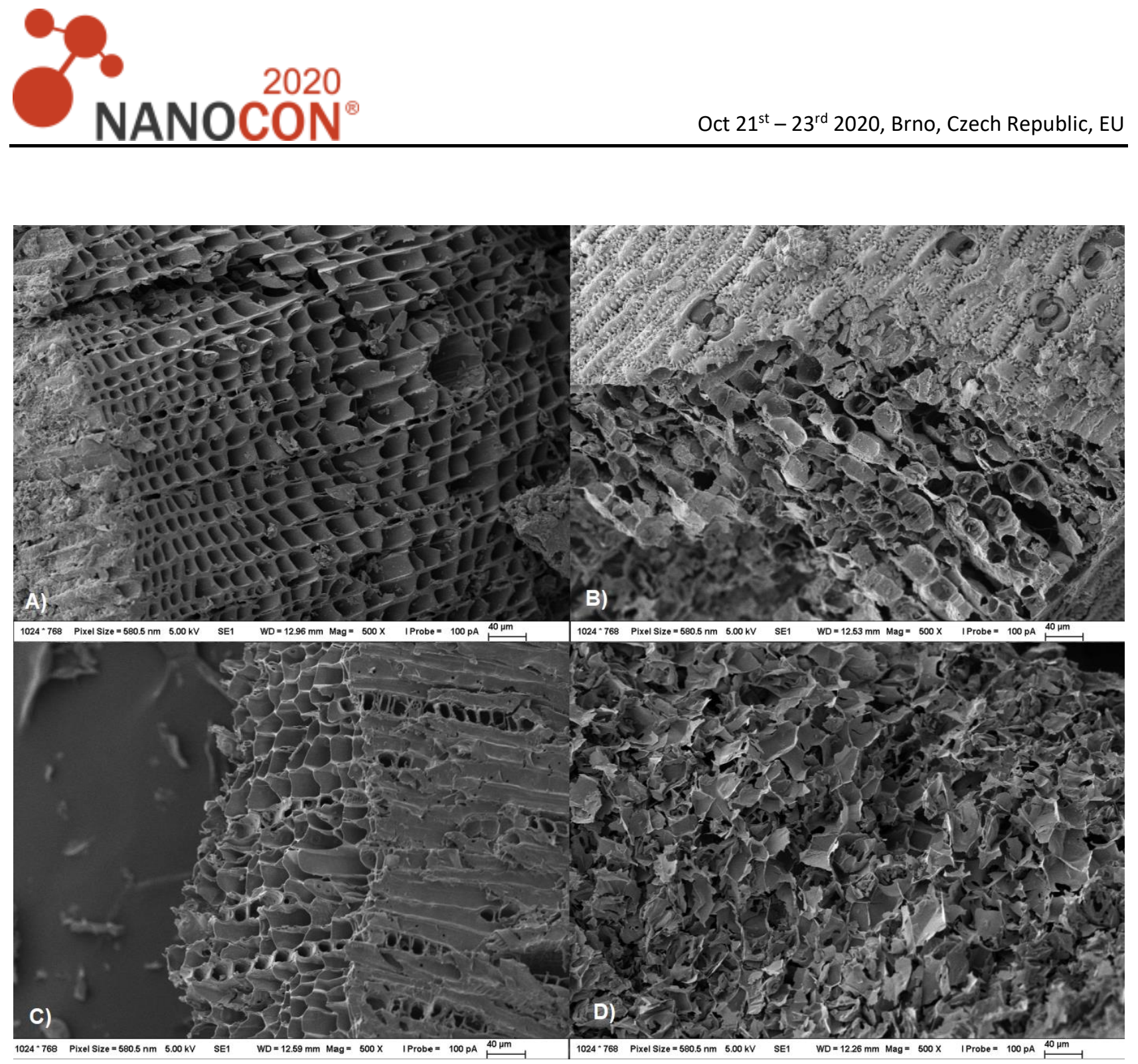

Figure 1 SEM images of the internal structure of Biochar 3 (magnification $500 x$ ) for $A$ ) fraction $A, B$ ) Fraction $B, C)$ Fraction $C$ and D) Fraction $D$ as were obtained by sieve fractionation

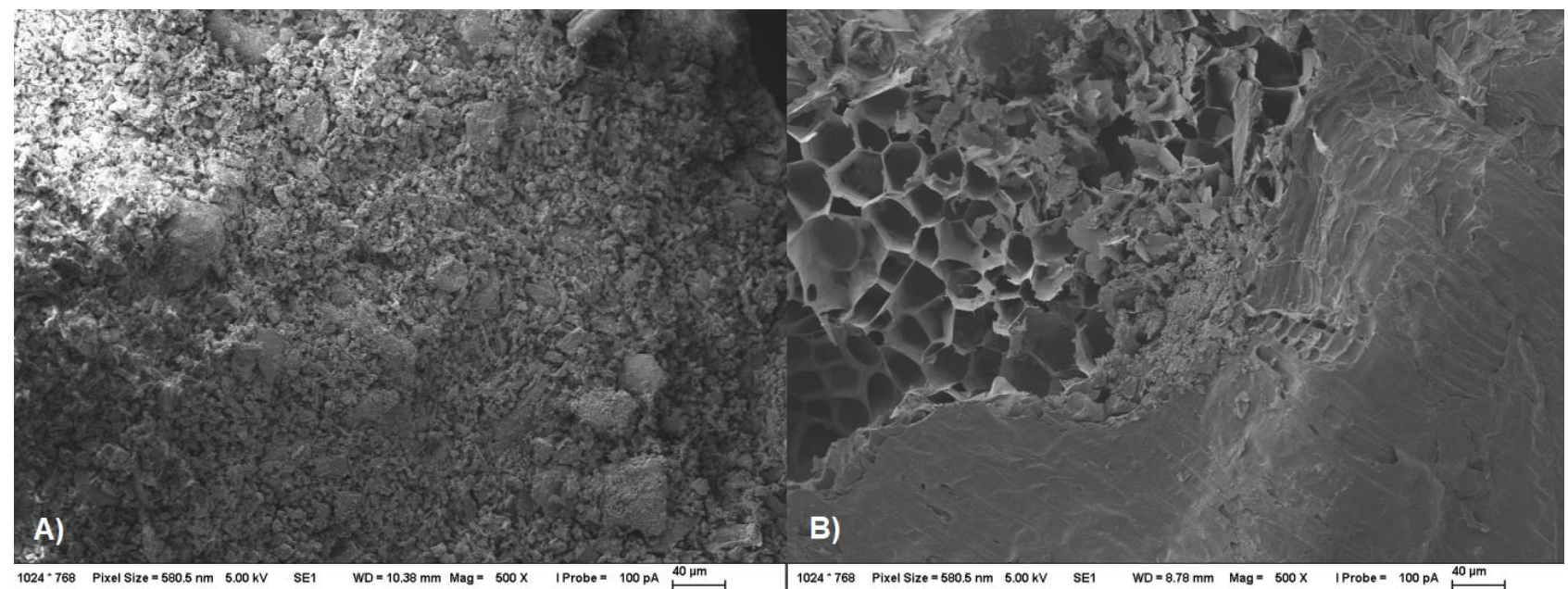

Figure 2 SEM images of the internal structure of A) Biochar 1 and B) Biochar 2 (data for fraction C)

The relation of biochar internal structure to its texture was studied also from the view of BET analysis providing information about the sample-specific surface area. The comparison of the results obtained for all the studied samples concerning the fraction of sieved material is shown in Figure 3. 


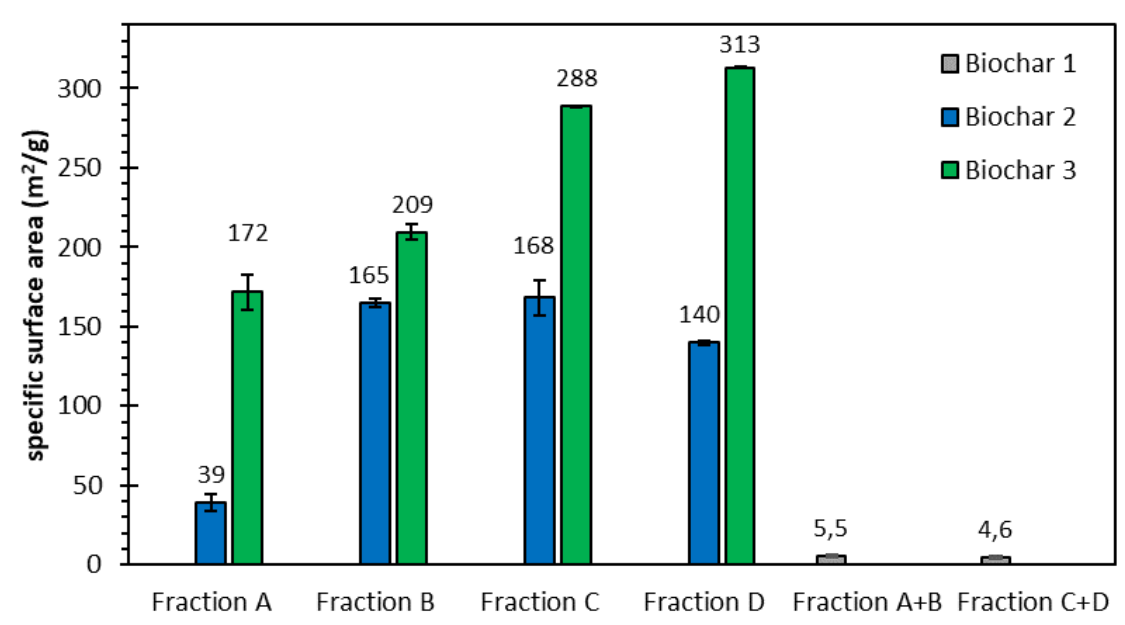

Figure 3 The relation of biochar specific surface area to its texture as was determined by BET analysis

The results from BET analysis are in good correlation with SEM imaging. The highest surface area determined by $B E T$ analysis were obtained for the most coarse fractions $(B, C, D)$. The biochar produced with the grain sizes above $0.5 \mathrm{~mm}$ has a more developed porous internal structure. Such a coarse material with developed internal structure has higher sorption and water retention potential, which is desirable for the use in agriculture. The surface area analysis also confirmed that the sample of Biochar 1 has significantly less developed internal microporous structure in comparison with certified EBC Biochar samples 2 and 3.

\subsection{Relation of biochar texture to its organic matter content}

The biochar samples were studied regarding their potential utilization in agriculture as soil conditioners. Their role in soils could be found mainly in the improvement of physicochemical properties, the content of organic matter, the sorption ability of nutrients and the water holding capacity. The last three characteristics of soils are connected with the content of organic matter and organic carbon [5]. By these reasons, the studied biochar samples were characterized also by thermogravimetric and elemental analysis (Table 1).

Table 1 Total organic ( $W_{\text {org }}$ ) and inorganic ( $W_{\text {inorg }}$ ) content) and elemental composition of biochar samples in respect to the sample texture (recalculated on a dry sample)

\begin{tabular}{|c|c|c|c|c|c|c|c|}
\hline \multirow{2}{*}{ sample } & \multirow{2}{*}{ texture } & \multirow{2}{*}{ Worg (wt.\%) } & \multirow{2}{*}{$\begin{array}{c}W_{\text {inorg }} \\
\text { (wt.\%) }\end{array}$} & \multicolumn{4}{|c|}{ Elemental composition (wt.\%) } \\
\hline & & & & C & $\mathbf{H}$ & 0 & $\mathbf{N}$ \\
\hline \multirow{2}{*}{ Biochar 1} & Below $2 \mathrm{~mm}$ & 70.35 & 29.65 & 45.39 & 7.54 & 15.06 & 2.36 \\
\hline & Above $2 \mathrm{~mm}$ & 78.98 & 22.84 & 56.40 & 2.38 & 15.29 & 3.10 \\
\hline \multirow{4}{*}{ Biochar 2} & Below $0.5 \mathrm{~mm}$ & 67.86 & 32.14 & 59.97 & 0.81 & 5.39 & 1.70 \\
\hline & $0.5-2.0 \mathrm{~mm}$ & 72.93 & 27.07 & 67.66 & 0.94 & 2.33 & 2.00 \\
\hline & $2.0-4 \mathrm{~mm}$ & 78.96 & 21.04 & 71.72 & 2.00 & 2.93 & 2.31 \\
\hline & Above $4 \mathrm{~mm}$ & 77.42 & 22.58 & 65.66 & 1.61 & 7.05 & 3.09 \\
\hline \multirow{4}{*}{ Biochar 3} & Below $0.5 \mathrm{~mm}$ & 71.44 & 28.56 & 63.40 & 1.57 & 4.69 & 1.78 \\
\hline & $0.5-2.0 \mathrm{~mm}$ & 82.56 & 17.44 & 74.48 & 1.63 & 4.54 & 1.92 \\
\hline & $2.0-4 \mathrm{~mm}$ & 91.08 & 8.92 & 84.34 & 2.62 & 2.39 & 1.73 \\
\hline & Above $4 \mathrm{~mm}$ & 81.23 & 18.77 & 73.27 & 2.64 & 3.97 & 1.34 \\
\hline
\end{tabular}


The obtained results are indicating that total organic matter is increasing in all studied biochar samples with the increasing coarseness of the fraction as was obtained by sieve fractionation. The increase in the total content of organic matter correlates with an increase in the total content of organic carbon, indicating the higher potential of fractions containing more coarse fractions of particles for the use in agriculture. EA and TGA analysis confirmed also similar content of organic matter and organic carbon of EBC certified samples of Biochar 2 and 3. On the other hand, a sample of Biochar 1 possessed a higher content of hydrogen and oxygen indicating less aromatic and more aliphatic structure with a higher content of $\mathrm{O}$-bearing functional groups.

\section{CONCLUSION}

The results of the work are indicating that the development of the internal structure of biochar can be correlated to the specific internal area and the coarseness of biochar. These parameters together represent important characteristic with respect to the possible utilization of biochar in agriculture. More developed internal structure means higher sorption potential of a sample and higher water holding capacity. Moreover, the more developed porous internal structure can be correlated also to the total content of organic matter and organic carbon, which is again important parameter in respect to the use of biochar as a potential soil conditioner.

\section{ACKNOWLEDGEMENTS}

This work has been supported by project GJ20-28208Y from Czech Science Foundation.

\section{REFERENCES}

[1] ZEESHAN, M., AHMAD, W., HUSSAIN, F., AHAMD, W., NUMAN, M., SHAH, M. and AHMAD, I. Phytostabalization of the heavy metals in the soil with biochar applications, the impact on chlorophyll, carotene, soil fertility and tomato crop yield. Journal of Cleaner Production. 2020, vol. 255.

[2] YANG, C.D. and S.G. LU, S. Effects of five different biochars on aggregation, water retention and mechanical properties of paddy soil: A field experiment of three-season crops. Soil and Tillage Research. 2021, vol. 205.

[3] YANG, W., FENG, G., MILES, D., GAO, L., JIA, Y., LI, C. and QU, Z. Impact of biochar on greenhouse gas emissions and soil carbon sequestration in corn grown under drip irrigation with mulching. Science of The Total Environment. 2020, vol. 729.

[4] SIEDT, M., SCHÄFFER, A., E.C. SMITH, K., NABEL, M., ROSS-NICKOLL, M. and T. VAN DONGEN, J. Comparing straw, compost, and biochar regarding their suitability as agricultural soil amendments to affect soil structure, nutrient leaching, microbial communities, and the fate of pesticides. Science of The Total Environment. 2021, vol. 751.

[5] ZHU, X., LI, Y. and WANG, X. Machine learning prediction of biochar yield and carbon contents in biochar based on biomass characteristics and pyrolysis conditions. Bioresource Technology. 2019.

[6] RAZZAGHI, F., OBOUR, P.B. and ARTHUR, E. Does biochar improve soil water retention? A systematic review and meta-analysis. Geoderma. 2020, vol. 361.

[7] ZACCHEO, P., CRIPPA, L. and C. CATTIVELLO, C. Liming power of different particle fractions of biochar. Acta Horticulturae. 2014, vol. 1034, pp. 363-368.

[8] NEMATI, M., SIMARD, F., FORTIN, J. and BEAUDOIN, J. Potential Use of Biochar in Growing Media. Vadose Zone Journal. 2015, vol. 14, no. 6, pp. 1-8.

[9] PRASAD, M., CHRYSARGYRIS, A., MCDANIEL, N., KAVANAGH, A., GRUDA, N. and TZORTZAKIS, N. Plant Nutrient Availability and $\mathrm{pH}$ of Biochars and Their Fractions, with the Possible Use as a Component in a Growing Media. Agronomy. 2020, vol. 10, no. 1.

[10] The European Biochar Certificate (EBC). [online]. Arbaz, Switzerland: Ithaca institute of carbon strategies. [viewed 2020-10-15]. Available from: https://www.european-biochar.org/en/home. 